Revista Iberoamericana, Vol. LXXVIII, Núm. 240, Julio-Septiembre 2012, 637-656

\title{
EL ENSAYO ENTRE PARÉNTESIS: ROBERTO BOLAÑO Y EL OLVIDO DE LA MODERNIDAD LATINOAMERICANA
}

\author{
POR \\ Oswaldo Zavala \\ College of Staten Island, CUNY
}

A pesar de la fama internacional y el éxito comercial que goza actualmente la obra de Roberto Bolaño (1953-2003), resulta interesante recordar que hasta la aparición de Los detectives salvajes (1998) su carrera literaria había recibido una muy limitada atención crítica. Bolaño había publicado hasta ese momento el catálogo imaginario de escritores fascistas La literatura nazi en América, la novela Estrella distante (ambos en 1996) y el libro de cuentos Llamadas telefónicas (1997). Jorge Herralde, editor español de la mayor parte de la narrativa de Bolaño, explica que, aún después de la relativa notoriedad que obtuvo con estos libros, no es sino a partir del éxito de Los detectives salvajes que Bolaño se convirtió en la celebrada figura de las letras hispanoamericanas que es hoy. ${ }^{1}$ Esta novela le valió dos de los reconocimientos más importantes que un novelista puede recibir tanto en Latinoamérica como en España: el premio Rómulo Gallegos, ${ }^{2}$ otorgado en Venezuela, y el premio Herralde, ofrecido por la casa editorial Anagrama, ${ }^{3}$ en Barcelona. Desde entonces, anota el crítico español Ignacio Echevarría, Bolaño comenzó a recibir invitaciones para colaborar en medios españoles y latinoamericanos,

1 Herralde recuerda, por ejemplo, que Estrella distante, una de sus más aclamadas novelas cortas, vendió en todo el mundo, incluyendo Latinoamérica, solamente 951 ejemplares en su primer año, 816 en el segundo y 818 en el tercero (42).

2 La lista de ganadores del premio Rómulo Gallegos (siguiendo los años en que ha sido otorgado de manera irregular) incluye a algunos de los autores más reconocidos en los últimos cuarenta años, como los escritores del boom: Mario Vargas Llosa por La casa verde (1967), Gabriel García Márquez por Cien años de soledad (1972) y Carlos Fuentes por Terra Nostra (1977). Otros de los premiados son el mexicano Fernando del Paso por Palinuro de México (1982), así como los españoles Javier Marías por Mañana en la batalla piensa en mí (1995) y Enrique Vila-Matas por El viaje vertical (2000). Para una lista completa de los ganadores, véase el sitio del Centro de Estudios Latinoamericanos Rómulo Gallegos (Celarg): <http://www.celarg.org.ve/Espanol/Premio\%20Romulo\%20Gallegos.htm>.

3 El premio Herralde fue creado en la década de 1980 y ha sido otorgado a escritores latinoamericanos como los mexicanos Sergio Pitol por El desfile del amor (1984) y Juan Villoro por El testigo (2004), y los argentinos Alan Pauls por El pasado (2003) y Martín Kohan por Ciencias morales (2007). Para un documento sobre la historia del premio, véase: $<$ http://www.anagrama-ed.es/PDF/XXV_aniv_premi. $\operatorname{pdf}>$. 
dictar conferencias y participar en congresos y en presentaciones de libros, entre otras actividades literarias (Entre paréntesis 7). El volumen Entre paréntesis (2004), editado póstumamente por el mismo Echevarría, reúne estos textos antes dispersos: columnas periodísticas, crónicas de viaje, discursos de aceptación de premios y algunos escritos que han sido leídos como autobiográficos pero que inicialmente fueron concebidos como relatos de ficción. ${ }^{4}$ Echevarría considera la colección como una "cartografía personal" y una "autobiografía comentada” (Entre paréntesis 7). Esta clasificación, sin embargo, difícilmente puede aceptarse para un libro tan complejo que no sólo pone en duda la naturaleza del ensayo autobiográfico sino que, como discutiré en lo que sigue, radicaliza la tradición misma de la ensayística latinoamericana contemporánea.

Vale la pena comenzar con un breve recorrido sobre el ensayo autobiográfico en Latinoamérica y la manera en que esta tradición transforma al género ensayístico. Esta transformación es un precedente de las estrategias textuales que utilizan los textos de Bolaño, algunos de ellos estructurados como notas autobiográficas, pero que principalmente operan como ensayos literarios en Entre paréntesis. Inicio con el breve análisis que Alfonso Reyes elabora sobre la naturaleza del retrato. En esas páginas, Reyes propone que el retratista, inmerso en el flujo del tiempo, intenta capturar la esencia última del sujeto retratado. Pero al ser confrontado con la inminencia de su propia finitud, la urgencia del autorretrato "condensa" la memoria del sujeto y cobra una nueva dimensión "con vistas a la posteridad" ("Parrasio" 325). Ante la muerte, el retrato se convierte, según Reyes, en una abstracción que deviene en hecho estético: "El retrato se desprende de su modelo, como el edificio de su andamio y echa a vivir por cuenta propia" ("Parrasio” 326). En las letras latinoamericanas, el ensayo autobiográfico ha corrido una suerte análoga a la tradición del retrato en coyunturas históricas muy precisas. Desde la "Respuesta a Sor Filotea" (1691), de Sor Juana Inés de la Cruz, a las Memorias de Fray Servando Teresa de Mier $(1876,1917),{ }^{5}$ el sujeto discurre sobre la frágil consolidación de su individualidad y aborda críticamente su entorno sociopolítico. Pasadas las guerras de independencia, la autobiografía se utiliza con fines políticos durante los procesos fundacionales de los estados latinoamericanos. Escritos por estadistas que se asumen como modelos depositarios de la nación, los ensayos autobiográficos son también

4 Me detendré más adelante en dos lecturas de críticos estadounidenses que han producido polémicas sobre aspectos de la biografía de Bolaño. Más allá de la controversia extra-literaria, me interesan estos probables casos de misreadings, sobre todo como factores de tensión del vínculo entre autor, personaje y narrador en su obra ensayística.

5 Christopher Domínguez Michael anota que la primera edición completa de los escritos de Fray Servando Teresa de Mier fue publicada por José Eleuterio González en 1876 con el título Biografía del benemérito mexicano don fray Servando Teresa de Mier Noriega y Guerra. Alfonso Reyes publicó en 1917 una nueva edición en la Biblioteca Ayacucho con el título Memorias, citado con mayor frecuencia por los especialistas y adoptado en varias ediciones subsecuentes (Domínguez Michael 559).

\footnotetext{
Revista Iberoamericana, Vol. LXXVIII, Núm. 240, Julio-Septiembre 2012, 637-656 ISSN 0034-9631 (Impreso) ISSN 2154-4794 (Electrónico)
} 
vehículos de proyectos personales de gobierno, uno de cuyos ejemplos paradigmáticos puede leerse en los Recuerdos de provincia (1850), de Domingo Faustino Sarmiento. En la tradición mexicana moderna, el libro más emblemático de esta genealogía es, sin duda, Ulises criollo (1935), de José Vasconcelos. Lo mismo programa individual del ciudadano modelo que metáfora de un fallido proyecto de nación, esta autobiografía sintetiza y cancela todos sus precedentes. Más allá de la tiranía colonial y las dinámicas de poder entre subalternos, después de las fisuras irreparables entre las naciones de reciente creación, Vasconcelos proyecta la desolación de quien asume la conciencia plena de la modernidad: el imposible transplante del legado occidental a América que sólo un adelantado consigue vislumbrar, y que, como Alfonso Reyes, reclama una ciudadanía universal entendida en términos puramente occidentales por los miembros del Ateneo de la Juventud. ${ }^{6}$

La segunda mitad del siglo xx verá la radicalización y agotamiento de este proceso. El ensayo autobiográfico El arte de la fuga (1996), de Sergio Pitol, produce un nuevo sujeto americano que no reclama una identidad occidental, sino que se dedica a experimentarla. El narrador-personaje de esta colección de textos se embarca en un dilatado viaje de más de veinte años en el que su condición criolla pierde densidad al igual que la personalidad occidental de sus interlocutores. El retrato de Occidente que construye El arte de la fuga vuelve irreconocible su modelo hasta transformarlo en otro. A partir de la obra de Pitol, tres libros de ensayo han tenido un efecto similar en la tradición latinoamericana: Formas breves (1999) del argentino Ricardo Piglia, Efectos personales (2000) del mexicano Juan Villoro y, desde luego, Entre paréntesis de Bolaño.

Desde el tema del exilio hasta la recomposición heterodoxa del canon, Bolaño lleva a cabo un descentramiento de la tradición latinoamericana del mismo modo en que Pitol deconstruye las verticalidades del legado occidentalista en México. Propongo en estas páginas recorrer algunos de los dispositivos textuales más importantes con los que Bolaño consigue olvidar los presupuestos de la modernidad por medio de una relectura de la obra de Borges y de un muy subjetivo canon alterno del siglo xx. Primero me detendré en la genealogía literaria en la que debe ubicarse Entre paréntesis, sobre todo a partir de la obra ensayística de Pitol. Después me acercaré a algunos de los ensayos con los cuales Bolaño subvierte la influencia del boom y sus epígonos, recupera la obra prácticamente olvidada de escritores de culto y contradice toda posibilidad de nacionalismo en las letras latinoamericanas. Finalmente discutiré cómo, a través de sus ensayos, Bolaño desautoriza el legado borgeano en escritores de su generación para imponer su propia

6 El Ateneo de la Juventud estuvo conformado por un grupo de intelectuales que promovieron la herencia cultural de Occidente como proyecto de modernización en México durante las primeras décadas del siglo xx. Además de Reyes y Vasconcelos, participaron también el filósofo Antonio Caso, el novelista Martín Luis Guzmán y el crítico literario Pedro Henríquez Ureña, entre otros. Más adelante me detendré en la visión occidental de Reyes específicamente.

\footnotetext{
Revista Iberoamericana, Vol. LXXVIII, Núm. 240, Julio-Septiembre 2012, 637-656 ISSN 0034-9631 (Impreso) ISSN 2154-4794 (Electrónico)
} 
lectura en función de su proyecto narrativo personal. Como analizaré en lo que sigue, Bolaño revela un ars poetica basado en un axioma cercano al concepto de la fuga articulado por Pitol: "El exilio real”, escribe, "es el valor real de cada escritor" (Entre paréntesis 50). Como escritor autoexiliado de la tradición, el olvido de Bolaño implica un profundo proceso de relecturas que activan marcadamente los presupuestos que se propone sobrepasar, recordando para el lector precisamente aquello que deberá ser suprimido. Su condición de excéntrico es parte medular de una poética desarticuladora de las dinámicas de poder en los circuitos literarios hispanoamericanos que la fuerza discursiva de sus ensayos pone, en más de un modo, entre paréntesis.

\section{De la Fuga aL PARÉNTESIS}

En su célebre estudio El deslinde, Alfonso Reyes propone un esquema sobre lo que él llama literatura “ancilar”, en el cual un texto no-literario (por ejemplo, el ensayo) puede llevar a cabo un "préstamo poético-total" que ocurre cuando el texto asume mecanismos propios de la literatura (49). Según Reyes, esta última clasificación se ejemplifica en la estructura del "ensayo literario", género que funciona como una "literatura aplicada" del modo en que la elocuencia del orador tenía un alto valor y centralidad en el mundo grecolatino (49). Contraviniendo a Reyes en este punto, José Luis Martínez anota por su cuenta que la dimensión subjetiva del género ensayístico puede considerarse como una forma adicional del deslinde entre la literatura y su función ancilar. Explica Martínez:

En los ensayos más puros y característicos cualquier tema o asunto se convierte en problema íntimo, individual; se penetra de resonancias humanas, se anima a menudo con un toque humorístico o cierta coquetería intelectual. (10)

Esta visión promueve aquí una sutil corrección a la teoría del deslinde: mientras que para Reyes el discurso literario se distingue de la función ancilar cuando la literatura “expresa lo humano”, Martínez hace prevalecer el género ensayístico al relacionarlo precisamente con ese concepto mismo de lo humano. Así, aunque la no-literatura (en este caso, el ensayo), según Reyes, exprese al hombre "en cuanto es teólogo, filósofo, cientista, historiador, estadista, político, técnico, etcétera” (41), el ensayo literario, estructurado como un préstamo poético-total y reconfigurado por la subjetividad exacerbada desde la perspectiva de Martínez, se convierte en "puro” y su aplicación se transforma en literatura por ser íntimo e individual.

En el siglo xx latinoamericano, Ulises criollo-como después El arte de la fuga y Entre paréntesis-es un ejemplo fundacional de este tipo de ensayo. En su fracaso político como candidato a la presidencia, derrotado en 1929 por el proyecto que instalaría el más fuerte discurso nacionalista en México, Vasconcelos intenta la reconfiguración de su identidad como un ejemplo de la voluntad nietzscheana y como interlocutor legítimo del

Revista Iberoamericana, Vol. LXXVIII, Núm. 240, Julio-Septiembre 2012, 637-656
ISSN 2154-4794 (Electrónico) 
más avanzado pensamiento occidental de su época. Crítico y superador de la corriente positivista que combatió junto con los demás miembros del Ateneo de la Juventud, Vasconcelos dedica varias páginas a discutir una teoría del conocimiento que según él congregaría distintas disciplinas bajo una explicación ontológica y cristiana del ser, y que al mismo tiempo guiaría sus acciones durante los turbulentos años de la revolución. Sus impulsos pasionales, sus convicciones políticas y sus condiciones biográficas pronto se entrelazan con la articulación de su teoría, como si la fuerza narrativa de su memoria impusiera un orden distinto al previsto por sus ideas.

Una sección de El arte de la fuga aparece como introducción en las más recientes ediciones de Ulises criollo publicadas por la editorial Porrúa. En ese texto, Pitol narra su primera lectura adolescente y su subsecuente relación con la obra de Vasconcelos que sirve a la vez como uno de los momentos clave de su formación literaria. Pitol no esconde sus reparos ante los prejuicios europeizantes y racistas que encuentra en esas páginas, pero también se fascina por la insólita capacidad de Vasconcelos de salir y volver al México bronco en plena revolución, y sin descuidar sus intereses intelectuales. Escribe Pitol:

Tal era su vida y eso resultaba prodigioso, que conspirara un día a favor o en contra de Pancho Villa para en el capítulo siguiente saberlo estudiando a Plotino o a Pitágoras en Nueva York, o recorriendo las salas del Museo Metropolitano después de repasar aplicadamente su Burckhardt para mejor comprender a los pintores italianos del Renacimiento. ${ }^{7}$ (281-282)

Esta descripción es desde luego tan aplicable a la vida y obra de Pitol como a la de Bolaño. Ignacio Echevarría anota que El arte de la fuga es claramente uno de los precedentes más inmediatos de la ensayística bolañesca, junto con el ya mencionado libro de Ricardo Piglia, Formas breves. Si a Pitol le impresiona la movilidad extrema de Vasconcelos, el concepto de la fuga articulado por Pitol es una estrategia textual presente en los ensayos de Bolaño. Pitol recuerda en retrospectiva la composición de El arte de la fuga en su tercer libro de memorias, ${ }^{8}$ El mago de Viena (2005), y lo llama "una

7 Es interesante notar aquí la preferencia de Pitol por Vasconcelos, dejando de lado a otros miembros del Ateneo de la Juventud que incursionaron con mayor éxito en la narrativa, como es el caso de Martín Luis Guzmán y aún de Alfonso Reyes. Ulises criollo, así, debe comprenderse como una anomalía profunda en relación a la producción de los demás miembros del Ateneo que sentó un nuevo precedente crucial para el perfil de escritor e intelectual que configura Pitol en El arte de la fuga.

8 El arte de la fuga es el primero de tres libros de memorias reunidos en la Trilogía de la memoria. Las citas provienen de este último volumen. En mi artículo "La síntesis y su trascendencia: Sergio Pitol, la escritura autobiográfica y el fin del occidentalismo” (RILCE. Revista de filología Hispánica 28/1 [2012: 256-271) desarrollo los rasgos más interesentaes de El arte de la fuga siguiendo de cerca el planteamiento crítico de la presente investigación. Pitol publicó poteriormente Una autobiografía soterrada (Ampliaciones,

\footnotetext{
Revista Iberoamericana, Vol. LXXVIII, Núm. 240, Julio-Septiembre 2012, 637-656 ISSN 0034-9631 (Impreso) ISSN 2154-4794 (Electrónico)
} 
summa de entusiasmos y desacralizaciones que a medida que transcurre se convierte en resta” (479). Este recorrido pronto asume la metáfora de la fuga que Pitol formaliza como una poética en la que vale la pena extenderse:

Los manuales clásicos de música definen la fuga como una composición a varias voces, escrita en contrapunto, cuyos elementos esenciales son la variación y el canon, es decir, la posibilidad de establecer una forma mecida entre la aventura y el orden, el instinto y la matemática, la gavota y el mambo. En una técnica de claroscuro, los distintos textos se contemplan, potencian y deconstruyen a cada momento, puesto que el propósito final es la relativización de todas las instancias. (479-80)

Por medio de la “fuga” Pitol no sólo se revela a sí mismo secretos resguardados por la memoria, sino que reconsidera los caóticos encuentros con personalidades literarias en exóticos y extraños escenarios que propulsaron los andamios de su obra narrativa. Pitol se aventura en décadas errantes como traductor, diplomático y simple viajero por Europa Oriental y Occidental. Por sí solo, su tránsito deconstructivista a través de la cultura europea desde luego no cancela su identidad y vocación occidental. Es en el momento de la escritura, en la articulación de una poética de ciudadanía a la vez global y personal, cuando Pitol resignifica las ansiedades (pos)occidentales del escritor latinoamericano:

Uno, me aventuro, es los libros que ha leído, la pintura que ha visto, la música escuchada y olvidada, las calles recorridas. Uno es su niñez, su familia, unos cuantos amigos, algunos amores, bastantes fastidios. Uno es una suma mermada por infinitas restas. (42)

Pitol sugiere aquí la configuración de un sujeto cuyas circunstancias biográficas son desplazadas por sus experiencias culturales y el azar de sus relaciones personales. Los ensayos de Roberto Bolaño pueden entenderse con mayor complejidad después de lecturas como el pasaje anterior. Tomemos como punto de partida el primer texto de Entre paréntesis, titulado “Autorretrato”. Bolaño comenta en la primera línea haber nacido en 1953, año de la muerte del dictador soviético Josef Stalin y del poeta Dylan Thomas. Las dos referencias son de inmediato sometidas a la imagen de un sueño que Bolaño dice haber tenido en el improbable escenario de un bar del Distrito Federal, con las dos figuras compitiendo por ver quién resiste la mayor cantidad de alcohol. El poeta y el dictador son presa de su propio cliché: Dylan Thomas bebe whisky y Stalin vodka, mientras que Bolaño evade el resultado final del concurso, asqueado. Este procedimiento, aunque apenas insinuado aquí, proporcionará a Bolaño la oportunidad

rectificaciones y desacralizaciones). (México: Almadía, 2010). Este último y breve libro puede leerse como coda o epílogo de su trilogía autobiográfica. Por cuestiones de espacio y por lo poco que agregaría a la presente investigación, he preferido no abordarlo.

Revista Iberoamericana, Vol. LXXVIII, Núm. 240, Julio-Septiembre 2012, 637-656
ISSN 2154-4794 (Electrónico) 
de subvertir la autoridad literaria y política en que transitan los argumentos de cada uno de sus textos. Las figuras hegemónicas de la historia política y cultural de Latinoamérica y Europa aparecerán literalmente entre paréntesis: es decir, suspendidas en un espacio de radical descontextualización que culmina con su resignificación siempre a favor de una alternativa sociocultural promovida por Bolaño con objetivos muy específicos, generalmente en torno a una ética personal como autor y sobre el acto de creación. En el caso del "Autorretrato", como explica Echeverría en una nota al final del libro, Bolaño escribe y envía el texto al Centro de Estudios Latinoamericanos Rómulo Gallegos, con motivo del premio de ese mismo nombre que obtuvo por su novela Los detectives salvajes, como se mencionó antes. Además de una breve semblanza y una ficha bibliográfica, el texto presenta a un escritor que más que reconocer sus genealogías, las reconfigura como plataforma genésica de su proyecto literario y, como se verá en otros textos, político e histórico.

Desde el trabajo de Roberto Fernández Retamar -la dialéctica del "Calibán" americano que utiliza la lengua europea para intentar una emancipación epistemológica de su subjetividad colonizada-hasta los textos de Walter Mignolo-la lectura poscolonial de la modernidad, entendida esta última como el proceso a través del cual Europa avanza "hacia la hegemonía mundial” (Idea xviii, mi traducción)-, el occidentalismo latinoamericano ha sido sometido a examen con vías a una progresiva deconstrucción. Más que continuar esta crítica, escritores como Vasconcelos, Pitol y Bolaño llevan a cabo una transformación radical en la manera en que el escritor latinoamericano contemporáneo puede relacionarse con la tradición occidental. Simultáneamente, esta relación se problematiza como parte del continuo proceso de avances y retrocesos que distingue a las muy variadas elucubraciones de lo nacional y la búsqueda de la modernidad, desde Facundo: Civilización y barbarie (1845), de Sarmiento, en el contexto argentino, hasta El laberinto de la soledad (1950), de Paz, en el mexicano. Sin experimentar lo que el crítico Carlos Alonso llama "la carga de la modernidad", el ciudadano (pos)occidental que crea Bolaño no utiliza la lengua española sólo para agredir la herencia colonial, como pretendía Fernández Retamar: más bien se observa a sí mismo y se hace presente como el articulador de sus propias dinámicas culturales, con arbitrariedad espontánea en algunos casos y con premeditación en otros. Escritor nacido en Chile, exiliado después en México y finalmente radicado hasta su muerte en

9 Mi traducción del título del libro de Alonso, que analiza la ambigüedad retórica de varios autores latinoamericanos que proponen y al mismo tiempo rechazan sus distintos proyectos de modernidad. Tal es el caso, entre otros escritores estudiados por Alonso, de Sarmiento y el proceso de europeización de Argentina, el llamado al abolicionismo de Domingo del Monte, la profesionalización del escritor que busca Quiroga y la transición al posmodernismo en la obra de Vargas Llosa (viii). Esta ambigüedad discursiva que observa a la modernidad al mismo tiempo como "ideal” y como "condena", es el fenómeno que da título al libro de Alonso, The Burden of Modernity.

ISSN 0034-9631 (Impreso) 
España, Bolaño detenta una condición americana que alterna con la europea pero que cede al cúmulo de lecturas, de relaciones personales, gustos estéticos, metas alcanzadas y fracasos estimulantes. En ese sentido, el sujeto que emerge de los ensayos de Bolaño discurre en tensión con el legado de la modernidad occidental con la misma fuerza con que Borges consigue instalar su poética como agente subversivo de los cánones europeos. Bolaño opera aquí como "un marginal en el centro, un cosmopolita en los márgenes” siguiendo el célebre estudio de Beatriz Sarlo sobre Borges y su obra (16), produciendo dos efectos paralelos: trastoca las verticalidades impuestas por el canon occidental, pero también somete a la tradición literaria moderna hispanoamericana a ese mismo impulso desestabilizador, como explicaré en lo que sigue.

\section{LA SUBVERSIÓN SIMBÓLICA DEL PARÉNTESIS}

En Las reglas del arte, Pierre Bourdieu traza la historia del emergente campo literario francés como el proceso activado por las figuras señeras de finales del siglo xIX para garantizar la relativa autonomía de una intelectualidad alternativa a los distintos aparatos de poder. Bourdieu estudia a Baudelaire, entre otros, como uno de los protagonistas centrales que a partir de una serie de subversiones simbólicas construye ese espacio alternativo a los discursos hegemónicos. Anota Bourdieu que Baudelaire "afirma su derecho a la consagración" entre los grupos vanguardistas y "también el derecho, e incluso el deber, que incumbe al portador de la nueva legitimidad, de revertir la tabla de valores" (109, mi traducción).

Entre paréntesis ofrece al lector textos en los que Bolaño revierte de manera resuelta la tabla de valores literarios de la segunda mitad del siglo xx. Después del "Autorretrato" preliminar, Echevarría divide el libro en seis secciones que combinan conferencias, presentaciones de libro, notas autobiográficas y, sobre todo, artículos periodísticos publicados en España y en varios países de Latinoamérica. Me detendré, siguiendo el orden del libro, en la primera sección titulada "Tres discursos insufribles", ${ }^{10}$ para después comentar algunos de los ensayos breves publicados como columnas en distintos periódicos. En el primer discurso "insufrible”, "Derivas de la pesada”, se analiza el panorama literario argentino pos Borges, es decir, la producción literaria que surge a partir de la muerte del escritor considerado por Bolaño como el más importante del siglo xx. Su objetivo es probar la inexistencia de la tradición nacional al afirmar que ninguna de las tres vertientes literarias de mayor presencia puede producir una corriente del mismo modo en que, por ejemplo, la obra de Borges y Bioy dialogaba con interlocutores dentro y fuera del país, o la manera en que el imaginario de la poesía gauchesca creó una época en sí misma. Las tres vertientes que le interesan -las obras de Osvaldo Soriano,

${ }^{10}$ La referencia aquí es el libro de cuentos de Bolaño publicado póstumamente, El gaucho insufrible (2003).

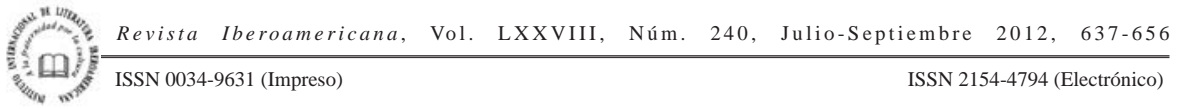


Ricardo Piglia y Osvaldo Lamborghini- escribe Bolaño, "representan un retroceso, son conservadores y no revolucionarios" (Entre paréntesis 25). Con esta postura, más allá de las implicaciones políticas, Bolaño acusa el facilismo de la novela policiaca que produce Soriano, el texto reducido a producto de consumo y entretenimiento carente de originalidad, pero no exento del atractivo del cliché, con "[u]n poco de humor, mucha solidaridad, amistad porteña, algo de tango, boxeadores tronados y Marlowe viejo pero firme” (Entre paréntesis 25). Más adelante, Bolaño indica que la influencia de Roberto Arlt en la narrativa de Piglia produce un hito anómalo que al igual que la obra sin precedentes de Osvaldo Lamborghini no puede generar sino una corriente derivativa y basada en la mala imitación y el plagio. Sin demeritar la obra de Arlt y Piglia, Bolaño afirma que el destino de ambos "es cabalgar solos por la pampa habitada por fantasmas" (30). Y luego concluye: "Allí, sin embargo, no hay escuela posible. Corolario. Hay que releer a Borges otra vez” (30). La lectura de Bolaño propone así una breve crítica del negocio editorial: el género policial en la actualidad se ha convertido en instrumento mercantil del éxito comercial de escritores como Soriano, y extrapolando de esta visión, de autores más jóvenes y en boga que Bolaño no menciona, como Pablo de Santis. Y aunque la obra de Ricardo Piglia o de César Aira sean felices anomalías que según Bolaño continúan la heterodoxia de Arlt y Lamborghini, esta tesis argumenta que ningún escritor joven puede aprender de escritores raros. De allí que el corolario del texto reenvíe a Borges: su relectura obligada implica que los presupuestos modernos de Borges han sido en el mejor de los casos incomprendidos, y en el peor, simplificados y banalizados en fórmulas de best-sellers. Bolaño manifiesta algo similar en la ponencia "Sevilla me mata", que no terminó pero que planeaba leer en un encuentro de escritores latinoamericanos jóvenes convocado en Sevilla en junio de 2003, ${ }^{11}$ a semanas de su muerte. En ese texto, afirma que los escritores jóvenes profesan un ansia de "respetabilidad" (Entre paréntesis 311) por la que están dispuestos “en cuerpo y alma a vender” (Entre paréntesis 312). Luego se pregunta:

¿Qué no vende? Ah, eso es importante tenerlo en cuenta. La ruptura no vende. Una escritura que se sumerja con los ojos abiertos no vende. Por ejemplo: Macedonio Fernández no vende. Si Macedonio es uno de los tres maestros que tuvo Borges (y Borges es o debería ser el centro de nuestro canon) es lo de menos. Todo parece indicarnos que deberíamos leerlo, pero Macedonio no vende, así que ignorémoslo. (312)

Este llamado de Bolaño a la relectura de Borges, no obstante, debe analizarse en relación a sus efectos en el campo literario latinoamericano: al desautorizar la narrativa de la

${ }_{11}$ Presentes en el encuentro estuvieron, en orden alfabético: Roberto Bolaño, Jorge Franco, Rodrigo Fresán, Santiago Gamboa, Gonzalo Garcés, Fernando Iwasaki, Mario Mendoza, Ignacio Padilla, Edmundo Paz Soldán, Cristina Rivera Garza, Iván Thays y Jorge Volpi. Véase: Palabra de América.

\footnotetext{
Revista Iberoamericana, Vol. LXXVIII, Núm. 240, Julio-Septiembre 2012, 637-656 ISSN 0034-9631 (Impreso) ISSN 2154-4794 (Electrónico)
} 
segunda mitad del siglo xx en Argentina, como hemos visto, Bolaño impone su lectura de Borges como la única viable, con el subtexto implícito de que sólo a través de un proyecto literario análogo al de sus ensayos (y por ende de su narrativa) puede recuperarse y continuarse el auténtico legado borgeano en la literatura latinoamericana actual.

La presencia de Borges en la obra de Bolaño funciona en este último sentido: sin aludirlo en forma más directa, Bolaño traza un vínculo genealógico directo entre su ensayística y la de libros de la mejor prosa borgeana, como Otras inquisiciones (1952). La literatura nazi en América entabla igualmente un diálogo crucial con la crítica al fascismo que Borges produjo en cuentos como "Deutsches Requiem", ${ }^{12}$ al igual que la novela 2666 (2004) y su relectura de la Segunda Guerra Mundial. Y así como es clara la relación entre el cuento "El gaucho insufrible" como reapropiación de "El Sur" de Borges, ${ }^{13}$ es también evidente la preferencia de Bolaño por la épica, género defendido por Borges como el más apto para la narrativa contemporánea ${ }^{14}$ y que Bolaño asimila sobre todo en sus dos novelas más importantes ya mencionadas, Los detectives salvajes y 2666. A pesar de su alta originalidad, sin embargo, la lectura de Borges hecha por Bolaño tiene por lo menos dos importantes precedentes que deben establecerse para comprender las fuentes de su visión literaria y la relación que ésta tiene con sus estrategias narrativas. El primer precedente es del mismo Ricardo Piglia, quien analiza la obra de Borges como la bifurcación que en la tradición argentina simboliza Facundo, de Sarmiento (la modernidad cosmopolita), y Martín Fierro (1872), de José Hernández (la épica nacionalista). Ante estos dos extremos, según Piglia, Borges "inventa un tipo de escritura, un estilo y una construcción que le permite mantener unidos los polos con sus redes antagónicas y opuestas"15 (Crítica y ficción 158). El segundo precedente de la lectura de Bolaño es el ensayo largo del también argentino Alan Pauls, El factor Borges (1999). En ese texto, Pauls señala la profunda ruptura que Borges significa para la literatura latinoamericana contemporánea y la urgencia de reconsiderar su influencia a lo largo de todo el siglo como el punto más radical de la modernidad, en el que las ficciones borgeanas "han ido demasiado lejos, han llevado el pensar y el pensamiento hasta el límite, un límite donde el pensamiento coincide con la imposibilidad de pensar" (147). Me interesa aquí contextualizar las dinámicas en el campo literario que producen reapropiaciones paralelas y en competencia por el legado de Borges para mostrar cómo en el caso de Bolaño estas dinámicas orientan su obra ensayística hacia una crítica que anula las tradiciones nacionales a partir de un intento personal de crear precursores,

12 "Deutsches Requiem” está incluido en el libro de cuentos El Aleph (1949).

13 Publicado primero en La nación, en 1953, el cuento “El Sur” forma parte de Ficciones desde su segunda edición de 1956.

${ }^{14}$ Para un estudio detallado sobre el género épico en ambos autores, véase el artículo de Aura Estrada, "Borges, Bolaño and the Return of the Epic".

${ }_{15}$ Piglia presenta una tesis similar en su novela Respiración artificial (1980), en boca de su personaje Renzi.

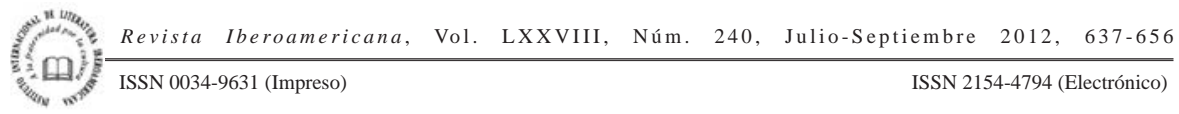


en el sentido más borgeano del término. ${ }^{16}$ Del mismo modo en que Borges declaró a Alfonso Reyes como el mayor prosista hispanoamericano, ${ }^{17}$ Bolaño celebra la obra de Borges para al mismo tiempo identificarla con su propio proyecto literario.

De esta deliberada reconfiguración del canon y su crítica a la literatura comercial, Bolaño arremete en el segundo texto "insufrible” contra toda versión de literatura nacional y sus autores más consagrados. Se trata del "Discurso de Caracas”, leído durante la ceremonia de entrega del premio Rómulo Gallegos. ${ }^{18}$ En un tono marcadamente lúdico e irónico, Bolaño juega con la posibilidad de recrear las tradiciones literarias de Venezuela y Colombia a partir de aliteraciones con los nombres de lugares y personas. Caracas debería ser así la capital de Colombia, y La casa verde, de Mario Vargas Llosa, debe ser leída como una novela colombiano-venezolana, al igual que Doña Bárbara del mismo Rómulo Gallegos es, siguiendo esta lógica, una novela absolutamente venezolana, pero también con vínculos directos a la capital de ese país, que, según Bolaño, es Bogotá. Luego afirma la posibilidad de que bajo el influjo de su evidente dislexia:

[...] se esconda un método, un método semiótico bastardo o grafológico o metasintáctico o fonemático o simplemente un método poético, y que la verdad es que Caracas es la capital de Colombia así como Bogotá es la capital de Venezuela, de la misma manera

${ }^{16}$ Lo mismo ocurre en la actualidad, irónicamente, con el legado del propio Bolaño y la manera en que ha sido disputado a través de lecturas canonizantes que reclaman su figura como parte de ciertas genealogías. Tal es el caso de la compilación Palabra de América (2004) publicada con las ponencias presentadas durante el encuentro de escritores latinoamericanos jóvenes en Sevilla, antes mencionado. En la contraportada de ese libro se explica que el congreso fue un "hito generacional” cuyo "animador primero” fue Bolaño, a quien también desean "tributar un homenaje” con el mismo volumen. Por su parte, el escritor boliviano Edmundo Paz Soldán coeditó la reciente antología de ensayos críticos Bolaño salvaje (2008), en la que el mexicano Jorge Volpi discute con acidez la obra de Bolaño como objeto de constante reapropiación por las nuevas promociones de escritores latinoamericanos. No está de más recordar que ambos Paz Soldán y Volpi también participaron en el congreso de Sevilla.

17 En su biografía literaria de Borges, Emir Rodríguez Monegal recuerda que con su admiración por Alfonso Reyes y Paul Groussac, Borges también utilizaba a ambos autores como símbolos del tipo de escritor que prefería y el estilo que deseaba asimilar (246). Al mismo tiempo, Rodríguez Monegal recuerda que Borges consideró el estilo desmesurado y elíptico de Macedonio Fernández como "una mala influencia en su escritura", a pesar de haber sido inicialmente su mentor y modelo en una etapa temprana de su carrera (218). Dentro de este mismo juego genealógico, que conlleva su cuota de cautela, puede comprenderse el hecho de que Borges afirmara que el estilo de Groussac y Reyes no quedó “íntegramente en ningún libro” que produjera un hito en la tradición, como en el caso argentino de Sarmiento y Facundo (Vázquez 209). Independientemente de esta crítica, como explica Amelia Barili, Borges y Reyes forman una "comunidad discursiva” que produce una correspondencia entre sus proyectos poéticos (32-33). Ese mismo vínculo debe notarse entre Borges y Bolaño, por lo menos en la manera en que este último construye su obra declarando abiertamente su asimilación de la influencia borgeana.

18 La ceremonia se llevó a cabo en Caracas el 2 de agosto de 1999, según indica Ignacio Echevarría en las notas bibliográficas de cada uno de los ensayos incluidos en Entre paréntesis. Todas las referencias e información sobre los discursos de Bolaño incluidos en el libro provienen de estas notas.

Revista Iberoamericana, Vol. LXXVIII, Núm. 240, Julio-Septiembre 2012, 637-656
ISSN 2154-4794 (Electrónico) 
que Bolívar, que es venezolano, muere en Colombia, que es también Venezuela y México y Chile. (Entre paréntesis 34; énfasis mío)

El tercer discurso “insufrible” culmina el proceso de esta gradual descentralización y vaciamiento de las tradiciones nacionales a través de su "método poético”. Bolaño lee la conferencia "Literatura y exilio" durante un simposio titulado "Europa y América Latina: literatura, migración e identidad”, organizado en Viena por la Sociedad Austriaca para la Literatura. ${ }^{19}$ Bolaño comienza recordando al poeta mexicano Mario Santiago, que durante un viaje a finales de 1970 fue deportado de Austria, sin la posibilidad de volver a ese país hasta 1984. De allí Bolaño cita un poema de Nicanor Parra que reemplaza los nombres de los cuatro poetas más importantes de Chile, lugares que con frecuencia ocupan, según Bolaño, Pablo Neruda, Gabriela Mistral, Vicente Huidobro y el mismo Nicanor Parra. Dice el poema: "Los cuatro grandes poetas de Chile / son tres: / Alonso de Ercilla y Rubén Darío” (Entre paréntesis 44). Bolaño señala que una de las “enseñanzas” del poema es:

[...] que probablemente nuestros dos mejores poetas, los dos mejores poetas chilenos, fueron un español y un nicaragüense que pasaron por esas tierras australes, uno como soldado y persona de gran curiosidad intelectual, el otro como emigrante, como un joven sin dinero, pero dispuesto a labrarse un nombre, ambos sin ninguna intención de quedarse, ambos sin ninguna intención de convertirse en los más grandes poetas chilenos, simplemente dos personas, dos viajeros. (Entre paréntesis 46)

La crítica al nacionalismo que Bolaño apenas había dejado entrever en su relato de la deportación de Mario Santiago, cuyo destierro duraría hasta el año orwelliano de 1984, se agudiza aquí para destronar a las figuras literarias fundadoras de la tradición chilena con la defensa provocadora de dos poetas extranjeros como los más relevantes en la literatura de un país ajeno.

Entre paréntesis presenta así a un sujeto articulador de gestos subversivos que se reconoce como el ciudadano activo de una nación transcontinental imaginada de un modo análogo a la manera en que Benedict Anderson estudia la formación del nacionalismo. ${ }^{20}$ El conjunto de la producción literaria de todos los países occidentales sumaría desde esta visión una identidad cultural compartida por la comunidad intelectual y en particular por ciudadanos multiculturales como Bolaño, que transita de una tradición a otra sin las limitaciones del nacionalismo y estableciendo, en cambio, diálogos horizontales con

${ }^{19}$ Bolaño leyó el discurso en Viena el 3 de abril de 2000. Véase Echevarría, Entre paréntesis.

${ }^{20}$ Me interesa aquí, entre otros, el mecanismo fundacional de una nación que se activa, según Anderson, en el momento en que un sujeto puede sentirse vinculado a otros a través de lecturas y de imaginarios compartidos. Véase sobre todo el segundo capítulo de Imagined Communities, “Cultural Roots,” para una lectura completa sobre este punto.

\footnotetext{
Revista Iberoamericana, Vol. LXXVIII, Núm. 240, Julio-Septiembre 2012, 637-656 ISSN 0034-9631 (Impreso) ISSN 2154-4794 (Electrónico)
} 
interlocutores que reducen su condición de extranjero a una mera circunstancia política. Así puede entenderse mejor su crónica del viaje de regreso a Chile en 1998, luego de veinticinco años de ausencia, desde el golpe de estado. Parte de este texto, no exento de humor negro, fue interpretado como un ataque personal contra la escritora chilena Diamela Eltit y su pareja, el ministro Jorge Arrate, portavoz del gobierno de Eduardo Frei, quienes habían invitado a Bolaño a una cena en su casa. La crónica, independientemente de su tono irreverente, es más bien un acercamiento al mundo intelectual chileno en la era de la democracia liberal, sobre todo en cuanto a las prácticas que lo vinculan al poder político y la implícita co-dependencia entre los escritores y la clase gobernante. El texto, como recuerda Echevarría en la nota correspondiente al final del libro, despertó ataques personales de figuras intelectuales asimiladas a los aparatos gubernamentales por medio de becas o prebendas públicas. El propio Bolaño señaló, en un texto inédito incluido en esa misma nota, que sus atacantes (a quienes no menciona por nombre) lo trataron de “cortesano” (Entre paréntesis 348) a pesar de jamás haber recibido apoyo oficial o cargos diplomáticos, como ha sido el caso de muchos escritores chilenos, como Pablo Neruda, Gabriela Mistral (ambos ganadores, además, del premio Nobel de literatura) y la misma Diamela Eltit, ${ }^{21}$ por mencionar a los de mayor éxito.

La parte más abundante de Entre paréntesis está integrada por las columnas periodísticas que Bolaño publicó en España y Chile a partir de 1998, cuando la publicación y el reconocimiento internacional de Los detectives salvajes comenzó a convertirlo en una celebridad y en un personaje público explosivo, como se explicó antes. Al igual que proponen lecturas personales de las obras de Twain, Turguéniev, Swift y Daudet, estos ensayos breves se adentran en autores latinoamericanos poco estudiados, excéntricos y virtualmente desconocidos fuera de sus contextos nacionales. Me detengo en algunos de ellos: al comentar El asco (1997), novela escrita por el salvadoreño Horacio Castellanos Moya, Bolaño se interesa por el estilizado y ácido humor con el que presenta una devastadora diatriba contra El Salvador, un libro que "se hace insoportable para los nacionalistas” (Entre paréntesis 172); de Sergio Pitol, Bolaño admira su condición de excéntrico: “[...] a diferencia de Carlos Fuentes y de otros contemporáneos suyos que gozaron de las mieles del boom, se mantuvo siempre un poco más allá, tanto en su producción, que en México no tiene par y que en el ámbito de la lengua española sólo es parangonable a la de muy pocos” (Entre paréntesis 135); al hablar de la prácticamente olvidada obra del ya mencionado Osvaldo Lamborghini, Bolaño no escatimó en el impresionismo terrorífico que le provocaba su lectura de este marginal autor de libros que parecen "bombas de relojería o animales falsamente disecados dispuestos a saltarte

${ }^{21}$ Además de los casos de Neruda y Mistral que creo innecesario detallar, Eltit fue agregada cultural en la embajada de Chile en México durante la presidencia de Patricio Aylwin (1990-1994), el gobierno que sucedió a la dictadura de Augusto Pinochet.

\footnotetext{
Revista Iberoamericana, Vol. LXXVIII, Núm. 240, Julio-Septiembre 2012, 637-656 ISSN 0034-9631 (Impreso) 은 ISSN 2154-4794 (Electrónico)
} 
al cuello en cuanto te descuides” (141). Es importante subrayar además el carácter dislocado de las columnas de Bolaño, muchas de ellas publicadas originalmente en catalán y para un público muy poco especializado.

La crítica argentina Celina Manzoni compara esta estrategia recreadora del canon latinoamericano con la publicación en 1896 de Los raros, el inventario de heterodoxos recogido por Rubén Darío. Manzoni explica que a los incluidos por Darío "los reúne su nombre, y por ese mismo acto los autoriza" (énfasis en el original), en un espacio literario en el que "la condición de raros, malditos o excepcionales es compartida" (341). Ese gesto reaparecerá en México décadas más tarde en la Antología de la poesía moderna editada por Jorge Cuesta, en 1928, con una serie de omisiones e inclusiones que tuvo su efecto durante la polémica de $1932^{22}$ entre nacionalistas y cosmopolitas en los círculos literarios de la época. Como en el caso paradigmático de Rubén Darío, Cuesta impone una visión personal del cosmopolitismo que termina por neutralizar ese debate, como es bien sabido, con un argumento irrefutable que marcó un hito definitivo en la historia literaria mexicana: "El nacionalismo es una idea europea que estamos empeñados en copiar. ¿Hasta qué punto corresponde en México a una realidad? ¿Hasta qué punto es una pura fantasía, un puro producto de la imitación de lo europeo?” (107). Cuesta produce una apertura en el campo literario, reclamando a su favor un nuevo canon. Entre paréntesis adopta el mismo gesto: desde una visión crítica que en la superficie es subjetiva y antojadiza, Bolaño construye un canon alterno donde distintos dominios y tradiciones aparecen mezcladas en un catálogo ad hoc, en apariencia espontáneo, pero diseñado a base de poéticas de resonancias complementarias, de ética compartida y de una actitud colectiva que configura objetos artísticos ajenos a los sancionados por los mercados literarios internacionales e ignorados (y en ocasiones atacados) por los centros del poder político.

En este sentido, los ensayos de Bolaño también ponen en tensión el pacto autobiográfico que describe Philippe Lejeune en su conocido estudio del género: Bolaño autor, narrador y personaje son parte de un mismo proceso desarticulador de tradiciones y nacionalismos en el cual la imposibilidad de autoidentificación plena lo ubica en un lugar de enunciación que es siempre otro. Es así que se explican, entre otras probables razones, las recientes controversias sobre la biografía de Bolaño y su supuesta adicción a la heroína, como también las dudas que se han planteado sobre el viaje a Chile que afirmó haber hecho en 1973, semanas antes del golpe militar de Augusto Pinochet. ${ }^{23}$

22 Véase: Guillermo Sheridan. México en 1932. La polémica nacionalista. México: Fondo de Cultura Económica, 2001.

${ }^{23}$ Esta versión fue sugerida en un artículo publicado en 2009 en The New York Times. El artículo cita al diplomático Ricardo Pascoe y a la novelista Carmen Boullosa, ambos mexicanos, quienes especulan que Bolaño pudo haber mentido sobre su viaje a Chile en 1973. Véase: Larry Rohter, “A Chilean Writer’s Fiction Might Include His Own Colorful Past”. Sin embargo, en un libro autobiográfico, el escritor

\footnotetext{
Revista Iberoamericana, Vol. LXXVIII, Núm. 240, Julio-Septiembre 2012, 637-656 ISSN 0034-9631 (Impreso) 
Más allá de las estrategias de mercadotecnia que pueden estar operando detrás de estas polémicas, resulta interesante que algunos críticos hayan llevado a cabo un misreading del texto titulado "Playa”, donde un narrador en primera persona menciona su adicción a la heroína. ${ }^{24}$ Así también Bolaño convierte en ficción, en un cuento incluido en Llamadas telefónicas ${ }^{25}$ (1997), el haber sido puesto en libertad de un campo de detención en Chile durante las primeras semanas del golpe por dos soldados que resultaron amigos de su juventud. El estatus entre el relato de ficción, el ensayo autobiográfico y la crónica de viaje con frecuencia aparecen deliberadamente confundidos en Entre paréntesis como estrategias narrativas que se gozan en la imposibilidad de la fijación, pero también en fluctuación inestable que va del autor al espontáneo narrador de un ensayo que adquiere también el perfil de personaje de ficción en un espacio literario ambiguo.

\section{EL OLVIDO DEL HERESIARCA}

El crítico Nicolás Cabral afirma que los ensayos de Entre paréntesis, sobre todo cuando abordan temas literarios, producen notas "repetitivas y banales" (87). El discurso "Literatura y exilio" mencionado antes, por ejemplo, es para Cabral una muestra de su "insólita y admirable habilidad para irse por las ramas" (87). Si el discurso bolañesco, de apariencia informal y en ocasiones contradictorio, sugiere una falta de rigor en la estructura de sus ensayos, esto podría explicarse también por la condición

chileno Jaime Quezada consigna que en efecto Bolaño llegó a Chile en la última semana de agosto de 1973, tras un largo viaje en autobús desde México. Quezada afirma haberlo recibido en su casa en Santiago, pero que el golpe militar sorprendió a Bolaño mientras visitaba a familiares en Los Ángeles y Mulchén, en el interior del país. Quezada escribe que la fachada de extranjero y el acento mexicanizado de Bolaño "le traerían momentos de ingratos pesares", "salvado sólo por fortuitas circunstancias de un ignorado destino” (116). Aunque no lo especifica, Quezada parece confirmar el episodio del arresto y encarcelamiento que Bolaño dice haber sufrido en manos de militares, así como su afortunada puesta en libertad por dos amigos de su juventud que lo reconocieron en el campo de detención, como mencionaré más adelante. En una entrevista, Bolaño confirma a su vez haberse quedado en casa de Quezada en Santiago, pero dice haber estado todavía allí el día del golpe: “[Quezada] Me despertó temblando y me dijo: ‘Roberto, han dado el golpe los militares’. Lo primero que recuerdo es decir: ‘¿dónde están las armas?, que yo me voy a luchar'. Y Jaime diciéndome: 'no salgas, no vayas, ¿qué le voy a decir a tu mamá si te pasa algo?’” (Quezada 105).

${ }^{24}$ Un ensayo sobre Bolaño publicado por la revista The New Yorker fue el primero en afirmar que Bolaño había sido adicto a la heroína y que esta adicción causó la enfermedad hepática que acabó con su vida. Un texto sobre esta interpretación apareció en el blog The Millions. Véase: <http://www.themillions. com/2008/11/was-bolano-junkie.html>. Andrew Wylie, el agente literario en Estados Unidos de Carolina López, la viuda de Bolaño, publicó una carta al editor de The New York Times aclarando a nombre de ambos que Bolaño "nunca sufrió de ninguna forma de adicción a las drogas" y que "Playa” es "verdaderamente una obra de ficción”, publicada originalmente por encargo en el periódico madrileño $E l$ mundo en julio de 2000. La aclaración apareció el 7 de diciembre de 2008. Véase <http://www.nytimes. com/2008/12/07/books/review/Letters-t-BOLAOSTUDIES_LETTERS.html>.

25 El cuento se titula "Detectives".

Revista Iberoamericana, Vol. LXXVIII, Núm. 240, Julio-Septiembre 2012, 637-656
ISSN 0034-9631 (Impreso) 2154-4794 (Electrónico) 
misma del simbólico gesto subversivo que está llevando a cabo en la tradición literaria hispanoamericana contemporánea. Mientras que algunos de los escritores más visibles en los últimos diez años han asumido agendas sociopolíticas claramente delineadas en la estructuración de sus proyectos literarios -aquí la obra de Jorge Volpi resulta el ejemplo más representativo ${ }^{26}$ - Bolaño avanza con una tensión e incertidumbre que según Bourdieu son propias del “artista herético”(111) que como Baudelaire desestabiliza todas las prácticas y convenciones literarias de su época. Entre paréntesis debe entenderse así no como un simple juego retórico de asociaciones inesperadas, sino como un complejo y gradual proceso de desarticulación de la tradición literaria hispanoamericana, cuyas resonancias pueden encontrarse también en la obra ensayística de escritores de su misma generación, como es el caso ya discutido de Pitol, Villoro, Pauls y Piglia. El proyecto herético de Bolaño podría estructurarse, en una primera lectura, como un ejemplo de las dinámicas del campo de producción cultural occidental que describe Pascale Casanova en su estudio sociológico de la literatura sobre lo que ella denomina como la "república mundial de las letras”. Esta visión mundialista, basada en las teorías de Bourdieu, propone la existencia de un centro de legitimación del capital simbólico global ubicado en París y que convierte al resto de Europa en la zona exclusiva del éxito literario. La capital francesa, según Casanova, es la codiciada meta última que intentan penetrar escritores de lenguas "minoritarias" (en este caso los latinoamericanos), de igual forma que en su momento obtuvieron carta de naturalización occidental -por medio del reconocimiento de los círculos intelectuales parisinos- autores como Jorge Luis Borges, pertenecientes a "espacios literarios indigentes"27 (280, mi traducción).

Una lectura atenta de los textos de Bolaño, no obstante, revela cómo éstos en realidad subvierten el modelo de Casanova, desmantelando y rearticulando distintos centros de producción y legitimación cultural (México, Santiago, Caracas, Bogotá) que dejan de lado la supuesta autoridad de París y analizan directamente la sofisticada y compleja poética de escritores latinoamericanos, como el caso de Borges, que el estudio de Casanova pasa por alto. Bolaño realiza un efectivo descentramiento de las capitales occidentales (ejemplificado en sus discursos pronunciados en Viena y Barcelona), normalizando su tránsito como agente al mismo tiempo autónomo y adscrito a sus muy diversas prácticas culturales. Leído así, es posible vislumbrar los objetivos políticos e históricos que su novela póstuma 2666 lleva a cabo al relacionar el holocausto de la

${ }^{26}$ Me refiero sobre todo al conjunto de novelas que Volpi ha llamado "Trilogía del siglo XX" y que incluye En busca de Klingsor (1999), El fin de la locura (2003) y No será la tierra (2006). Las novelas abordan temas históricos y culturales que van desde el proyecto atómico de la Alemania nazi, las revueltas estudiantiles de mayo de 1968 en París, hasta la disolución de la Unión Soviética, siempre desde una marcada perspectiva conservadora. Véase: Álvaro Enrigue. “El fenómeno Volpi, una meditación”.

${ }^{27}$ Para una extensa y detallada discusión sobre la propuesta de Casanova desde una perspectiva latinoamericana, véase: Ignacio Sánchez Prado, editor. América Latina en la "literatura mundial”.

Revista Iberoamericana, Vol. LXXVIII, Núm. 240, Julio-Septiembre 2012, 637-656
ISSN 0034-9631 (Impreso) 2154-4794 (Electrónico) 
Segunda Guerra Mundial con los asesinatos de mujeres en Ciudad Juárez, en la frontera norte de México. De allí que las ideas de Piglia sobre el discurso literario tengan también aquí una relación directa con esta novela cuando afirma que “[...] la literatura está siempre fuera de contexto y siempre es inactual; dice lo que no es, lo que ha sido borrado; trabaja con lo que está por venir. Funciona como el reverso puro de la lógica de la realpolitik” (“Qué va a ser”). 2666 pone en práctica narrativa estas ideas y acusa bajo esta mirada una verdad trascendental por encima de los registros históricos y los juegos geopolíticos, la Alemania nazi y el fallido estado neoliberal mexicano forman un binomio nefasto que revierte la noción del progreso en la modernidad del siglo xx: el asesinato de seis millones de judíos y de cientos de mujeres, independientemente de sus diferentes contextos, son fenómenos producidos por un mismo fracaso occidental compartido a la vez por México y por Alemania.

Quiero reconsiderar en su conjunto lo expuesto hasta aquí a modo de conclusión: libros como Entre paréntesis perpetran un vaciamiento del anclaje nacional que manifiestan los discursos y las circunstancias políticas e históricas de Sarmiento y Vasconcelos. Cancelan también la ansiedad de ser contemporáneos de todos los hombres que desde el pensamiento de figuras como Alfonso Reyes y Octavio Paz ha sido el mecanismo impulsador de la modernidad latinoamericana, la meta inasible que acusa con su ausencia la condición disfuncional del estado-nación y su cultura en vías de desarrollo. Al mismo tiempo, rebasa recientes articulaciones de lo pos-occidental, como lo que Walter Mignolo llama "border thinking” y que propone la superación de los sistemas binarios -margen/centro, colonizador/colonizado- que hacen prevalecer la condición subalterna de Latinoamérica. Entendido así, Entre paréntesis deja atrás la cortés petición castiza con la que Reyes solicita al "tribunal de pensadores internacionales" -es decir, a Europa- "reconocednos ${ }^{28}$ el derecho a la ciudadanía universal” ("Notas” 342) para ser un disruptivo elemento de apertura del campo literario en el que se explica también la aparición de libros como Safari accidental (2005) de Juan Villoro. Si al margen de esta corriente, colecciones de ensayos literarios como En esto creo (2002), de Carlos Fuentes, y Mentiras contagiosas (2008), de Jorge Volpi, resultan irrelevantes, esto se

${ }^{28}$ El texto original, publicado en 1936 en la revista Sur, aparece con el verbo en imperativo, en la forma de vosotros. En las más recientes reimpresiones de Última Tule, en el volumen XI de las Obras Completas de Reyes, el verbo ha sido cambiado al indicativo en la forma de nosotros: en lugar de "reconocednos" se lee ahora "reconocemos". La cita en el presente ensayo proviene, como se indica en la bibliografía, de la antología El ensayo mexicano moderno (1968) editada por José Luis Martínez. Este último anota que Martínez tomó “Notas sobre la inteligencia americana”, con el verbo en el imperativo original, de la primera edición de Última Tule publicada por Imprenta Universitaria en 1942. La cita original aparece con el verbo "reconocednos" en la página 145 de esa edición. El mismo Reyes cita "Notas sobre la inteligencia americana”, en un texto transmitido por radio sobre el otorgamiento del premio Nobel a Gabriela Mistral, utilizando de nuevo el "reconocednos" de la versión original en Sur y de la primera edición de Última Tule. Ese texto aparece en el volumen VIII de las Obras Completas 193-95.

Revista Iberoamericana, Vol. LXXVIII, Núm. 240, Julio-Septiembre 2012, 637-656
ISSN 0034-9631 (Impreso) 
debe a la imposibilidad de los sujetos de enunciación de ambos libros por superar la dialéctica del occidentalismo que desde sus dos extremos polarizantes -nacionalismo y cosmopolitismo- opera en forma análoga e irresoluta desde los albores del Modernismo a finales del siglo xix. El paréntesis bolañesco, en cambio, no busca reactivar el debate a favor del cosmopolitismo: se trata más bien de transitar horizontalmente dentro de una república intelectual quevulnera las jerarquías culturales y normaliza la condición exógena y supuestamente minoritaria del escritor latinoamericano y su tradición. En la búsqueda de la modernidad latinoamericana y su occidentalización siempre postergada, los proyectos literarios de autores como Bolaño convierten en obviedad el desenmascaramiento de los discursos nacionalistas que Roger Bartra, ${ }^{29}$ en el caso de México, ha llevado a cabo para descubrir las redes históricas del poder político e ideológico que operan en los andamios de los símbolos nacionales. Más que una solución en sí misma, la ensayística de Bolaño olvida el debate occidentalista que divide a cosmopolitas y nacionalistas, revierte toda posibilidad de verticalidad de la cultura y "se desprende de su modelo" como conjeturaba Alfonso Reyes sobre la naturaleza del retrato ("Parrasio" 326). Entre paréntesis traza su propia tradición, descentra los conglomerados de la producción cultural y sus espacios nacionales discursivos, perpetra actos de subversión simbólica que radicalizan los presupuestos de la modernidad, desestabiliza los géneros literarios y consigue la instalación del paréntesis como un apartado anómalo, pero también como una estrategia textual que cimbra la fijeza inamovible del punto final.

BiBLIOGRAFÍA

Alonso, Carlos. The Burden of Modernity: The Rhetoric of Cultural Discourse in Spanish America. Nueva York: Ofxord UP, 1998.

Anderson, Benedict. Imagined Communities. Nueva York: Verso, 2006.

Barili, Amelia. Jorge Luis Borges y Alfonso Reyes: la cuestión de la identidad del escritor latinoamericano. México: Fondo de Cultura Económica, 1999.

Bartra, Roger. La jaula de la melancolía. México: Sin Nombre/Conaculta, 2002.

Bolaño, Roberto. 2666. Barcelona, Anagrama, 2004.

Bolaño por sí mismo. Entrevistas escogidas. Andrés Braithwaite, ed. Santiago

de Chile: Universidad Diego Portales, 2006.

El gaucho insufrible. Barcelona: Anagrama, 2003.

Entre paréntesis. Ignacio Echevarría, ed. y notas. Barcelona: Anagrama, 2004.

La literatura nazi en América. Barcelona: Anagrama, 1996.

Llamadas telefónicas. Barcelona: Anagrama, 1997.

Los detectives salvajes. Barcelona: Anagrama, 1998.

${ }_{29}$ Véase: Roger Bartra. La jaula de la melancolía.

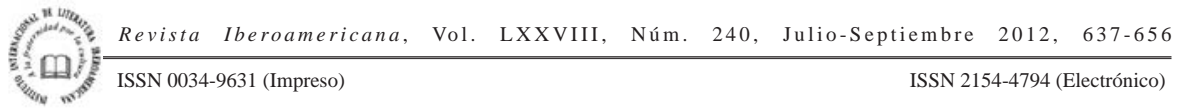


y otros. Palabra de América. Barcelona: Seix Barral, Fundación José Manuel Larra, 2004. Serie Los tres mundos, ensayo.

Bourdieu, Pierre. Les règles de l'art : genèse et structure du champ littéraire. [1992]. París: Seuil, 1998.

Cabral, Nicolás. “Paréntesis de un narrador”. Letras libres 69 (2004): 86-87.

Casanova, Pascale. The World Republic of Letters. Cambridge: Harvard UP, 2004.

Cuesta, Jorge. “La nacionalidad mexicana”. Poesía y crítica. Luis Mario Schneider, ed. México: Conaculta, 1991.

Domínguez Michael, Christopher. Vida de Fray Servando. México: Era e INAH, 2004.

Echevarría, Ignacio, ed. Entre paréntesis: ensayos, artículos y discursos (1998-2003). Roberto Bolaño. Barcelona: Anagrama, 2004.

Enrigue, Álvaro. “El fenómeno Volpi, una meditación”. Letras Libres 54 (2003): 69-70.

Estrada, Aura. “Borges, Bolaño, and the Return of the Epic”. Words Without Borders. 1 oct. 2006. <http://wordswithoutborders.org/article/borges-bolano-and-the-returnof-the-epic/>. 1 dic. 2010.

Fernández Retamar, Roberto. Calibán: apuntes sobre la cultura en nuestra América. México: Diógenes, 1971.

Fuentes, Carlos. En esto creo. Barcelona: Seix Barral, 2002.

Herralde, Jorge. Para Roberto Bolaño. México: Sexto Piso, 2005.

Lejeune, Philippe. Le pacte autobiographique. París: Seuil, 1996.

Manzoni, Celina. "Ficción de futuro y lucha por el canon en la narrativa de Roberto Bolaño”. Bolaño salvaje. Edmundo Paz Soldán y Gustavo Faverón Patriau, eds. Barcelona: Candaya, 2008. 335-357.

Martínez, José Luis. Introducción. El ensayo moderno mexicano. México: Fondo de Cultura Económica 1995. 312-30.

Mier Noriega y Guerra, José Servando Teresa de. Memorias. México: Conaculta, 2008. Mignolo, Walter. The Idea of Latin America. Oxford: Blackwell, 2005. Local Histories/Global Designs. Coloniality, Subaltern Knowledges, And Border Thinking. Princeton: Princeton UP, 2000.

Pauls, Alan. El factor Borges. Buenos Aires: Fondo de Cultura Económica, 2000.

Paz Soldán, Edmundo. Bolaño salvaje. Barcelona: Candaya, 2008.

Piglia, Ricardo. Crítica y ficción. Buenos Aires: Seix Barral, 2000. Formas breves. Buenos Aires: Temas Grupo Editorial, 1999. “Qué va a ser de ti”. Página 12.23 dic. 2001. <http://www.pagina12.com.ar/2001/ suple/Radar/01-12/01-12-23/NOTA2.HTM>. Marzo 2009. Respiración artificial. Buenos Aires: Pomaire, 1980.

Pitol, Sergio. Trilogía de la Memoria. Barcelona: Anagrama, 2007.

Quezada, Jaime. Bolaño antes de Bolaño: diario de una residencia en México. Santiago de Chile: Catalonia, 2007.

Revista Iberoamericana, Vol. LXXVIII, Núm. 240, Julio-Septiembre 2012, 637-656
ISSN 2154-4794 (Electrónico) 
Reyes, Alfonso. El deslinde. 1944. Obras completas vol. XV. México: Fondo de Cultura Económica, 1997.

"Parrasio o de la pintura moral”. 1940. El ensayo mexicano moderno. José Luis Martínez, ed. México: Fondo de Cultura Económica 1995. 312-30.

"Notas sobre la inteligencia americana". 1936. El ensayo mexicano moderno. José Luis Martínez, ed. México: Fondo de Cultura Económica 1995. 332-42.

Rodríguez Monegal, Emir. Jorge Luis Borges. A Literary Biography. Nueva York: E.P. Dutton, 1978.

Rohter, Larry. “A Chilean Writer's Fiction Might Include His Own Colorful Past”. The New York Times. 28 enero 2009: C1.

Sánchez Prado, Ignacio. América Latina en la "literatura mundial”. Pittsburgh: Instituto Internacional de Literatura Iberoamericana, 2006.

Sarlo, Beatriz. Borges, un escritor en las orillas. 1993. Buenos Aires: Seix Barral, 2007.

Vasconcelos, José. Ulises criollo. 1935. México: Porrúa, 2003.

Vázquez, María Esther. Borges, sus días y su tiempo. Buenos Aires: Javier Vergara, 1999.

Villoro, Juan. Efectos personales. México: Era, 2000.

Safari accidental. México: Joaquín Moritz, 2005.

Volpi, Jorge. Mentiras contagiosas: ensayos. Madrid: Páginas de Espuma, 2008.

Revista Iberoamericana, Vol. LXXVIII, Núm. 240, Julio-Septiembre 2012, 637-656
ISSN 0034-9631 (Impreso) 2154-4794 (Electrónico) 